\title{
Centers for \\ Marine Renewable Energy in Europe and North America
}

ABSTRACT. Since the late 1990s, there has been increased interest in marine renewable energy, such as wave and tidal current. Wave and tidal current energy has the potential to supply $15 \%$ of the UK's electricity needs, and in the United States the potential is about $7 \%$. Unlike wind, there is no single technological solution to harnessing energy from waves and tidal currents. As a result, many different devices are being developed, and so far there is no optimum solution. Because ocean energy systems operate in a harsh environment, there are significant engineering and environmental challenges to overcome. The UK Energy Research Centre Marine Renewable Energy Technology Roadmap classifies these challenges in terms of predictability, manufacturability, survivability, installability, affordability, and reliability. A number of centers and consortia throughout the world are working toward addressing these challenges, including the European Marine Energy Center (Scotland), SuperGen Marine Energy Research Consortium (UK), Hydraulics Maritime Research Centre (Ireland), Wave Hub \& PRIMaRE (South West England), Northwest National Marine Renewable Energy Center in Oregon and Washington (US), the Hawai'i National Marine Renewable Energy Center (US), and the Fundy Ocean Research Centre for Energy in the Bay of Fundy, Nova Scotia (Canada).

\section{INTRODUCTION}

The 1970s and 1980s yielded many pioneering scientific advances in marine renewables, but they were followed by a lapse in activity. Only since the start of this century have there been significant technological developments in both wave and tidal current energy. Today, a number of full-scale demonstration prototypes are being developed and installed around the world. Wave and tidal current energy has the potential to supply $15 \%$ of the UK's electricity needs (Carbon Trust, 2006), and in the US the potential is about $7 \%$ (Bedard, 2007). The literature contains good descriptions of the progression of wave and tidal current technologies to this point. In the wave energy field, nearshore and offshore devices have been deployed.
In order to assist in the building of a marine industry, a number of test facilities are now available from $1 / 100^{\text {th }}$ scale to full scale at sea. There has also been an increase in $\mathrm{R} \& \mathrm{D}$ spending in marine renewable research in those countries with the greatest access to the resource, namely the United Kingdom, Ireland, Portugal, and the United States, resulting in the formation of a number of research consortia and test centers, described in this article.

\section{RESEARCH CONSORTIA Supergen Marine}

Supergen Marine (http://www.supergenmarine.org.uk/news.php) is a consortium of UK academic institutions funded by the Engineering \& Physical Sciences Research Council (EPSRC) as part of its Sustainable Power Generation research program. The first phase of Supergen Marine started in 2003; the second phase commenced in September 2007 and is due to end in September 2011. There are five core academic partners in Phase 2: Edinburgh University (project lead), Queen's University Belfast, International 
Table 1. Supergen Marine Work Streams and Achievements

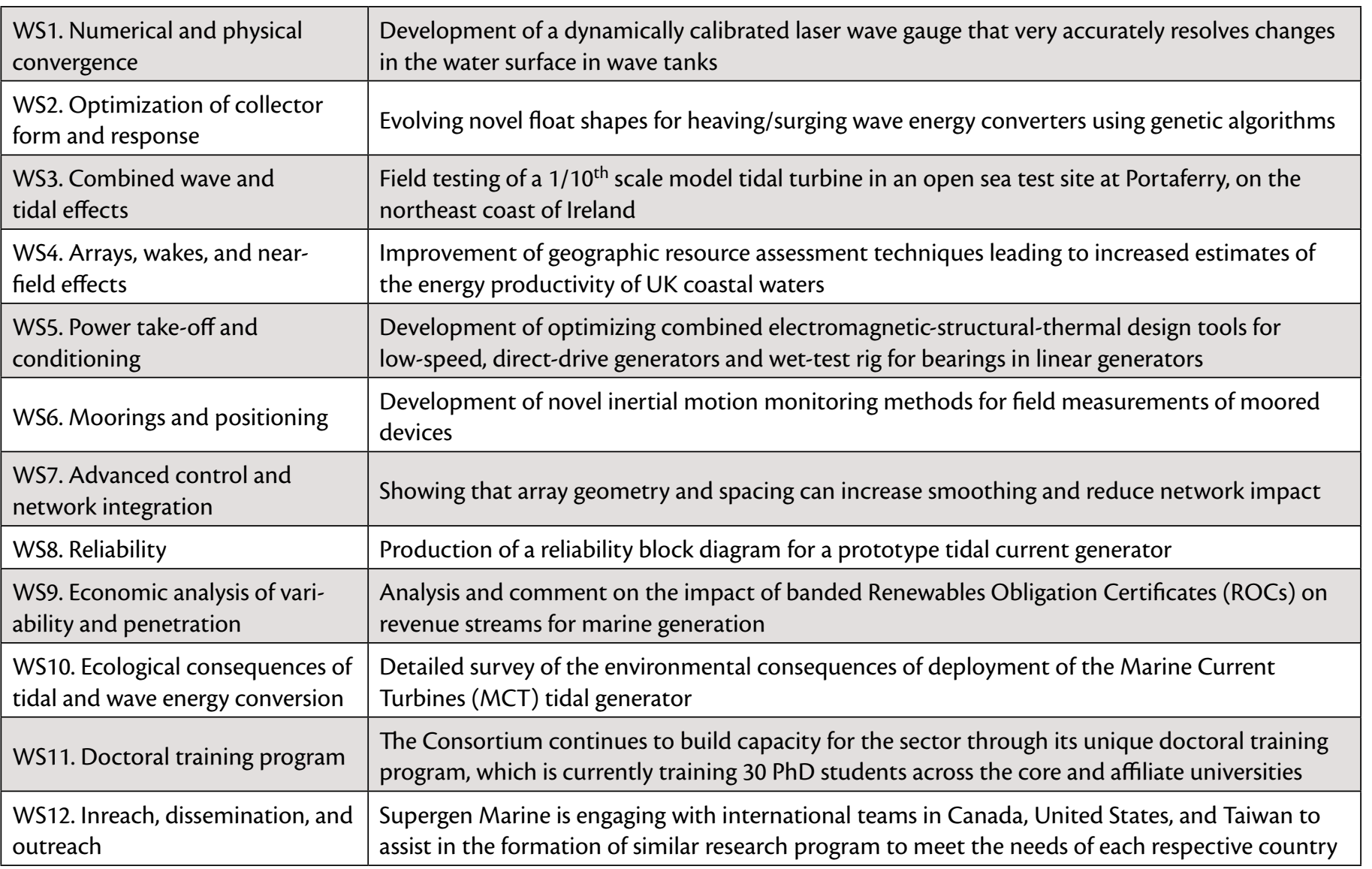

Centre for Island Technology (ICIT) Heriot Watt University, Lancaster University, and The Fraser of Allander Institute at Strathclyde University.

The consortium's main objective is to conduct generic research that supports the emerging industry with aims to:

- Increase knowledge and understanding of device-sea interactions of energy converters across the range of scales, from $1 / 100^{\text {th }}$ scale model tests to full-scale prototype devices

- Build capacity in and for the sector

- Internationalize effort and collaboration.

While focusing on generic sectorwide challenges, the consortium has strong links through its Research Advisory
Forum to test centers, equipment manufacturers, device developers, energy companies, and project developers. The work encompasses the full marine renewable energy chain from resource to wire, and considers both novel experimental techniques and the environmental impacts of energy extraction. Table 1 provides the 12 work streams with a statement of the main achievements in Phase 2 to date.

\section{Marine Renewable Energy Development in Scotland} Marine Renewable Energy Development in Scotland (MREDS; http://www.mreds. co.uk) is a joint academic-industry program led by ICIT on Orkney, and includes eight academic and five industrial partners. MRED's program has been designed to take advantage of its

Markus Mueller (markus.mueller@ ed.ac.uk) is Reader, Institute for Energy Systems, School of Engineering, University of Edinburgh, Edinburgh, UK. Henry Jeffrey is Research Associate, Institute for Energy Systems, School of Engineering, University of Edinburgh, Edinburgh, UK. Robin Wallace is Professor, Institute for Energy Systems, School of Engineering, University of Edinburgh, Edinburgh, UK. Annette von Jouanne is Professor, School of Electrical Engineering and Computer Science, Oregon State University, Corvallis, OR, USA. 
location on Orkney and its proximity to the European Marine Energy Centre's (EMEC) operations. There are six work packages: (1) export constraints, externalities, and opportunities; (2) petroleum and renewables; (3) mitigation, minimization, and management of risk; (4) hydrodynamics, moorings, and foundations; (5) environmental and ecological impacts; and (6) socio-economic values and responses.

\section{Peninsula Research Institute for}

\section{Marine Renewable Energy}

Peninsula Research Institute for Marine Renewable Energy (PRIMaRE; http:// www.primare.org) is a collaboration between Exeter and Plymouth universities, located in Cornwall, South West England, and linked directly to the Wave Hub (see later section on Wave Hub). As with Wave Hub, the institute is funded primarily by the South West Regional Development Agency research, it has identified six priority areas, which also have some links across areas: (1) Resource Characterization,

(2) Marine Renewable Energy Systems, (3) Environmental and Biodiversity Impacts, (4) Safe Operations and Navigational Risk, (5) Underwater and Surface Electrical Systems, and

(6) Socio-Economic Factors.

In order to support the theoretical work, in July 2009, PRIMaRE established a one-third-scale test facility to investigate mooring dynamics and alternative mooring designs in Falmouth Bay on the south coast of Cornwall. Results from this test facility will enable researchers to gain a better understanding of mooring design techniques specifically for wave energy devices. Wave tank test facilities are also being built to supplement the research. These tanks will provide multidirectional waves and variable currents at the same time for both shallow and deep waters. The main wave tank at the
College Cork, Southwest Ireland, was established in 1979. It is a center of excellence within Ireland for ocean renewables and coastal engineering, providing support to the maritime industry as well as fundamental $\mathrm{R} \& \mathrm{D}$. Its activities can be divided into four themes: (1) Coastal Engineering: coastal structures, coastal erosion, harbor engineering; (2) Offshore Engineering: offshore fixed and floating structures; (3) Coastal Resources: wave climate analysis, wave energy devices, pilot plant design; and (4) Support Activities: physical model construction, tank testing, data acquisition, numerical modeling.

In order to support these activities, a large ocean wave basin and wave flume are available at HMRC (the only such facilities in Ireland). These facilities allow the simulation of real sea waves, which are random in height, period, and direction. In order to reflect the multidisciplinary aspect of ocean energy, there is a wide range of engineering expertise at HMRC, including civil, environmental, electrical and electronic, mechanical, aeronautical, and oceanographic. HMRC works closely with technology developers to assist them in all aspects of their device development, through model testing, concept design, computer modeling, design performance validation, resource assessments, and offshore data recording. In addition to test tanks, they developed a one-quarter-scale test facility in Galway Bay (described later) in collaboration with Sustainable Energy Ireland and the Marine Institute. All devices to be installed at the site are required to undergo a rigorous evaluation of seaworthiness, which forms part of the development and evaluation protocol developed by HMRC. The protocol, which has now been adopted 
Table 2. Evaluation and development protocol for Ireland

\begin{tabular}{|l|l|l|}
\hline Phase 1 & Validation Model (lab) & Proof of concept. Test scale models (1:25-100) in wave tanks to prove theoretical predictions. \\
\hline Phase 2 & Design Model (lab) & $\begin{array}{l}\text { Test a larger scale model (1:10-25). Verify operation of the device. Model other aspects of the } \\
\text { device, such as power take-off. }\end{array}$ \\
\hline Phase 3 & Process Model & $\begin{array}{l}\text { Begin sea trials at a benign site or a very large wave tank facility at a scale between 1:3-15. } \\
\text { Demonstrate mooring systems and power take-off. }\end{array}$ \\
\hline Phase 4 & Prototype & $\begin{array}{l}\text { If the results from Phases } 1 \text { to } 3 \text { are favorable, a larger device can be built at a scale of 1:1-3 for } \\
\text { deployment at sea. }\end{array}$ \\
\hline Phase 5 & Demonstration & $\begin{array}{l}\text { Deploy a full-scale demonstrator at sea. Grid connection and electricity sale must be part of the } \\
\text { package. Some indication that the technology can be deployed in an array is also required. }\end{array}$ \\
\hline
\end{tabular}

by all wave developers in Ireland, provides a five-phase development plan (Table 2).

\section{Wave Energy Centre}

The Wave Energy Centre (WavEC; http://www.wavec.org) was founded in Portugal in 2003 as a private nonprofit organization to provide support to the marine renewable industry through technical and political strategies. WavEC is supported by a number of associates, who represent various aspects of the marine renewable industry, and includes utilities, technology developers, consultants, and academic institutions. The mission of WavEC is to provide technical support to associates by facilitating participation in national and European projects and forging links between the associates and other national and international organizations. In doing so, WavEC promotes the development of wave energy technologies, the exploitation of the wave resource, and is involved in training future scientists and engineers to serve the wave industry. WavEC has expertise in hydrodynamics of wave energy, numerical modeling, environment, monitoring, and communication. WavEC is also active in capacity building, being lead partner on the European Marie Curie Research Training
Network, WAVETRAIN. The second phase, started in October 2008, consists of 13 core partners and 18 associated partners from academic and industrial organizations all over Europe. It is funded under the "People" section of the EU Seventh Framework Programme (FP7) to address the technical and nontechnical challenges of industrialscale wave energy implementation. Researchers are employed in various work packages hosted by partners.

\section{TEST CENTERS}

\section{European Marine Energy Centre} The European Marine Energy Centre (EMEC; http://www.emec.org.uk) in Scotland was established as a result of a recommendation of the House of Commons Science \& Technology Select Committee in 2001. The center was officially opened in 2004 to provide open sea test facilities for wave and tidal current technology. Two test sites are available: (1) a wave test site at Billia Croo, Mainland Orkney, and (2) a tidal test site in the Fall of Warness off the island of Eday. Orkney was chosen because of its natural and manmade resources. The wave test site receives uninterrupted Atlantic waves of up to $15 \mathrm{~m}$. At the Eday site, tidal streams run at up to $4 \mathrm{~m} \mathrm{~s}^{-1}$ (8 knots) and are among the fastest in Europe. Orkney is also the most northerly community connected to the UK national grid, has excellent harbor facilities, and has a significant professional community experienced in working with renewable energy. In terms of deployment and testing, very few developers have experience in installation and environmental monitoring; thus, EMEC soon realized that the provision of additional services was very important, services that benefit not only the developers but also the wider marine renewable community. The main services offered for testing at EMEC are:

- Independent assessment of devices' energy conversion capabilities, structural performance, and survivability

- Assistance with grid connection and Renewables Obligation Certificate (ROC) accreditation

- Real-time monitoring of meteorological and marine resource conditions

- Extensive assistance with consent and regulatory issues

- Opportunity to join EMEC's monitoring strategy

- Extensive local research and engineering support

- Nearby access to sheltered water and harbors

- Office and data center support. EMEC is in a unique position in 
offering access to physical data from resource assessments, performance data from devices, and environmental data. In providing these services, EMEC is collaborating with a wide range of other institutions, including technology developers, the supply chain, academic institutions, and regulatory bodies. Provision of these services enables EMEC to work with other parties to assist in the verification and validation of modeling techniques for all aspects of device operation. This is important for the continuing development of the marine renewable industry. At the same time, EMEC remains independent of any particular technology developer.

Industry standards or guidelines are difficult to create without operational experience. EMEC's position as a test site operator has enabled it to coordinate the development of a suite of standards in collaboration with technology developers, regulators, academia, utilities, and project developers-a true cross section of the marine energy industry. These standards have recently been launched and are freely available from the EMEC Web site.

\section{The Northwest National Marine} Renewable Energy Center

The Northwest National Marine Renewable Energy Center (NNMREC; http://nnmrec.oregonstate.edu) is led by Oregon State University (wave energy), the University of Washington (tidal energy), and the National Renewable Energy Lab. NNMREC is a US Department of Energy Center, established in September 2008, to develop a full range of capabilities to support wave and tidal energy development for the United States. NNMREC will help move the generation of marine energy from the laboratory to an integral part of the renewable energy future.

The mission of NNMREC is to facilitate commercialization of marine energy technology, inform regulatory and policy decisions, and close key gaps in scientific understanding. Primary Center activities include: (1) development of facilities to serve as an integrated, standardized test center for US and international developers of wave and tidal energy, (2) evaluation of potential environmental, ecosystem, and social impacts, focusing on the compatibility of marine energy technologies in areas with sensitive environments and existing users, (3) device and array optimization for effective deployment of wave and tidal energy technologies, and (4) increased reliability and survivability of marine energy systems.

NNMREC serves multiple capacities and will develop knowledge and expertise in the following program areas:

- Advanced resource forecasting technologies (wave)

- Device and array optimization (wave/tidal)

- Collaboration and optimization among marine and other renewables (wave/tidal)

- Integrated test facilities for US and international developers (wave/tidal)

- Compatibility of marine power technologies and systems with the environment, fisheries, and other marine resources (wave/tidal)

- Increased reliability and survivability of marine power technologies (wave/tidal).

Currently, the US marine energy industry is challenged by the lack of proper and standardized infrastructure to test and deploy both wave and tidal devices in the ocean. The NNMREC wave and tidal test berths will provide developers with a resource to perform field testing as well as to demonstrate and advance subscale and full-scale systems. Figure 1 summarizes the NNMREC wave energy testing assets from small-scale to full-scale device development. Initially, the ocean wave energy test berths will be "mobile," with future plans to include both mobile and grid-connected capabilities. Deployment of the first mobile test berth is currently scheduled for late 2011 .

Test facilities for tidal energy technologies are at an earlier stage of development. Initial efforts have focused on accelerating industry development by deploying instrumentation to characterize the physical and biological environments at particular sites. At-sea test facilities are in the planning stage and will enable standardized demonstrations of tidal energy devices and environmental monitoring/mitigation technologies. Infrastructure will include subsea power and data cables to shore, junction boxes at each of the three berths, distributed environmental monitoring nodes, and one preplaced foundation in relatively shallow water $(20 \mathrm{~m})$. Peak currents at the proposed site range from 2-2.5 $\mathrm{m} \mathrm{s}^{-1}$.

\section{The Hawai'i National Marine}

Renewable Energy Center

The Hawaii i National Marine Renewable Energy Center (HINMREC; http:// hinmrec.hnei.hawaii.edu) was established to facilitate the commercialization of wave energy conversion (WEC) devices and to accelerate development and testing of ocean thermal energy conversion (OTEC) technologies. HINMREC supports design of OTEC precommercial plants and plans to provide WEC developers access to 


\section{NNMREC Wave Energy Scaling, Development, and Evaluation Resources}

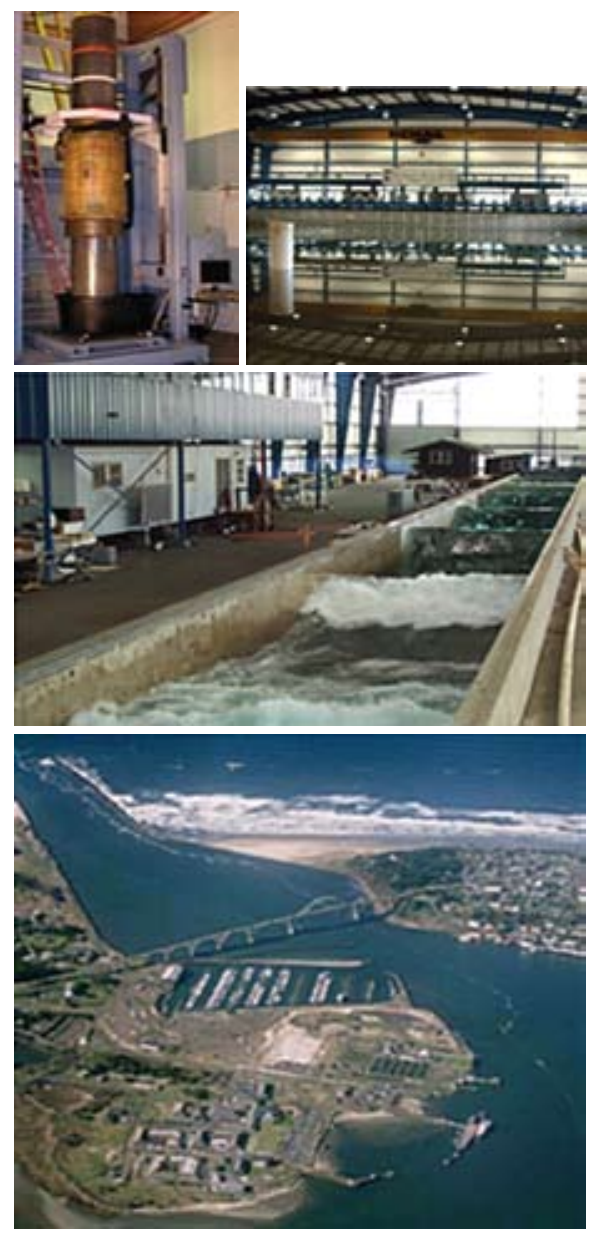

\section{Phase 1: Model Validation at OSU Facilities}

Phase 1a: $20 \mathrm{~kW}$ Wave Energy Linear Test Bed (WESRF), 2 m stroke

Phase 1b: Tank Testing in Regular and Irregular Waves (WRL)

Directional Tank (3D) Dimensions (m): $48.8 \mathrm{~L} \times 26.5 \mathrm{~W} \times 2.1 \mathrm{D}$

Max Wave: $0.8 \mathrm{~m}$ wave heights; $1 \mathrm{~m}$ water depth; $0.5-10 \mathrm{~s}$ periods

Scale $(\lambda): 1: 35-100$

\section{Phase 2: Advanced Model Validation at OSU Facilities}

Tank Testing in Regular and Irregular Waves (WRL)

Large Wave Flume Tank (2D) Dimensions (m): $104 \mathrm{~L} \times 3.7 \mathrm{~W} \times 4.6 \mathrm{D}$

Max Wave: $1.6 \mathrm{~m}$ wave heights; $3.5 \mathrm{~m}$ water depth; $0.5-10 \mathrm{~s}$ periods

Scale $(\lambda): 1: 15-50$

\section{Phase 3: Field Testing (Intermediate Scale)}

Yaquina Bay, OR: 0-0.2 m wind waves; $7.6 \mathrm{~m}$ water depth; $2-3 \mathrm{~s}$ periods

Puget Sound, WA: 0-1 m wind waves; $16 \mathrm{~m}$ water depth; $2-4 \mathrm{~s}$ periods

\section{Phase 4: Full-Scale Individual Device Testing and Demonstration (2010), Multiple Device Testing (up to 5, 2013)}

Newport, OR: 1-4 m waves; 40-50 m water depth; sandy bottom; 6-12 s periods Summer average: $1.5 \mathrm{~m}$ wave heights; $6-8 \mathrm{~s}$ periods Winter average: $3.5 \mathrm{~m}$ wave heights; $8-12 \mathrm{~s}$ periods

Figure 1. Northwest National Marine Renewable Energy Center (NNMREC) wave energy testing assets for scaled to full-scale device development. NMREC is led by Oregon State University, University of Washington, and the US National Renewable Energy Lab.

grid-connected berths under a variety of ocean conditions. HINMREC is primarily funded by the Energy Efficiency \& Renewable Energy Office of the US Department of Energy, through a five-year (2009-2014) contract awarded to the Hawai'i Natural Energy Institute at the University of Hawai'i.

HINMREC plans to establish and maintain several test sites in Hawai'i. A testing site for commercial size wave power systems is under development on the island of Maui. On Oahu, HINMREC presently operates two sites. The Kaneohe test site, presently occupied by Ocean Power Technologies
(OPT), will be expanded to incorporate a miniwave hub, providing berthing for as many as four WEC devices in the 100-500 kW range. Research on corrosion and biocorrosion of innovative materials is underway at the Makapu'u site. On the Big Island (Hawaiii), OTEC system component tests are underway.

The Makai Research Pier is located west of Makapu'u Point on the eastern tip of Oahu. HINMREC is currently conducting research on corrosion and biofouling of innovative materials there, and the site is easily accessible for deployment and testing of small wave energy conversion devices and components.
Fundy Ocean Research Centre for Energy

The Fundy Ocean Research Centre for Energy (FORCE; http://www.fundyforce. ca), located in the Bay of Fundy, Nova Scotia, Canada, focuses on in-stream tidal energy. The Bay of Fundy pushes over 100 billion tons of water every tide, which is more than all of the freshwater rivers and streams in the world combined. This environment creates exceptional conditions for developers, researchers, and the public to better understand the potential of in-stream tidal technology to deliver clean, renewable power. FORCE is a co-op of some of 
the world's leading researchers, scientists, developers, and regulators.

FORCE promotes innovation and development by lowering barriers to experimentation, demonstration, monitoring, and analysis of tidal energy generation. The FORCE group does this by providing common facilities and "soft infrastructure" such as permits and approvals, monitoring and environmental science, and know-how including:

- Shared infrastructure, services, insurance, environmental monitoring, and resource research

- A collaborative approach to environmental management

- An objective, nonprofit, and credible source of information

- A venue for engaging the entire range of stakeholders and partners that includes local communities, environmentalists, fishers, First Nations, regulators, scientific community, marine service industry, tourism, education, utilities, manufacturers, tidal in-stream energy developers, and the Province of Nova Scotia-the tidal resource owner.
The shared infrastructure will consist of three berths connected by submarine cable to a facility on shore that contains power-conditioning equipment. The facility will be connected either to the adjacent local distribution or directly to the Nova Scotia electrical grid via a purpose-built, 10-km transmission line. The $370-\mathrm{m}^{2}$ facility will house both a visitor center and research facilities.

New and Renewable Energy Centre The New and Renewable Energy Centre (Narec; http://www.narec.co.uk) is a national center for the UK based in Northeast England and dedicated to accelerating the deployment and grid integration of renewable energy and low-carbon-generation technologies, using wind, wave, tidal, solar photovoltaic (PV), and thermal power. The center works with a range of companies, from university spin offs to blue chip companies. Narec's marine test facilities consist of three drydocks that can be flooded; the smallest is used as a wave tank and the largest for subsea engineering work. Figure 2 shows an aerial view of the facility. The wave tank is $5.2-\mathrm{m}$ wide,

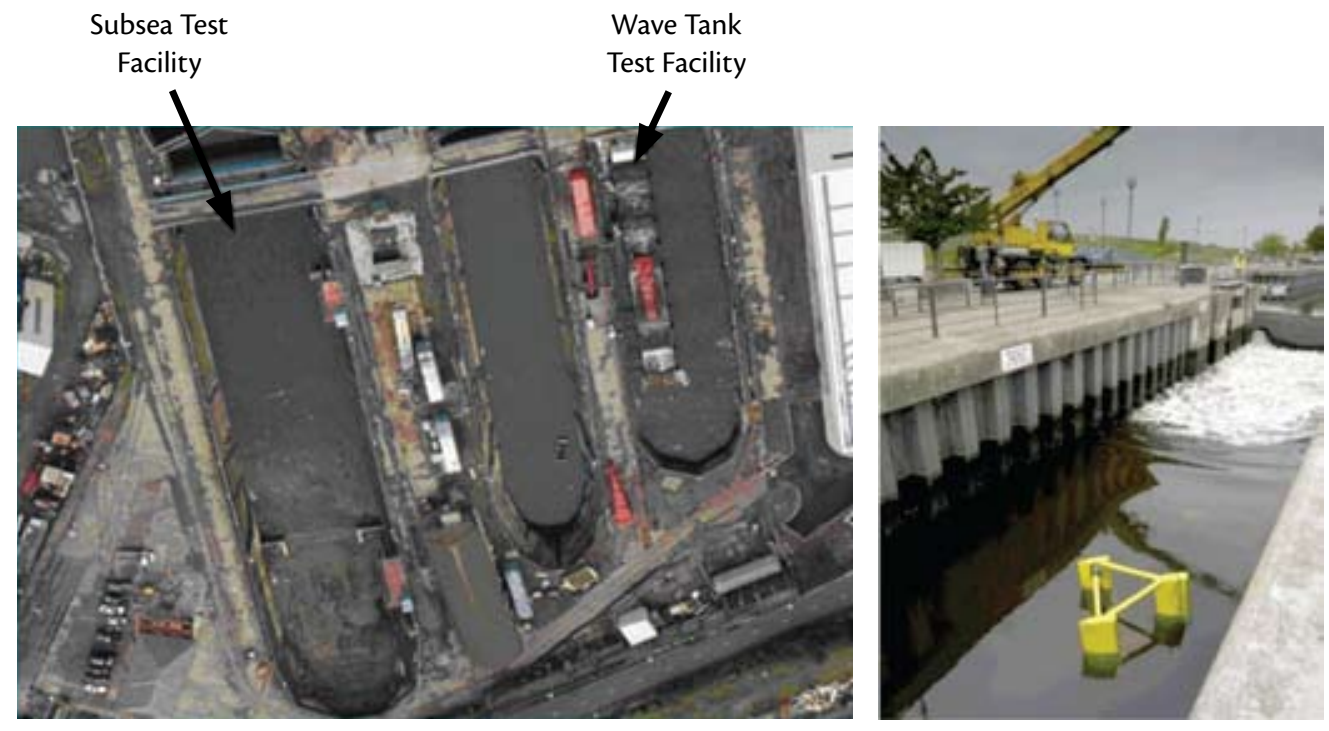

Figure 2. New and Renewable Energy Centre's wave, subsea, and tidal current test facilities in northeast England.
$5 \mathrm{~m}$ in length, and 4.2-7.2-m deep.

Wave heights of $0.8 \mathrm{~m}$ can be produced across a period range of $2-4 \mathrm{sec}$. In the subsea tank ( $125 \mathrm{~m} \times 25 \mathrm{~m} \times 8.25 \mathrm{~m})$, the nature of the seabed can be modified, and testing is in saltwater. The facility is ideal for remotely operated vehicles (ROVs), tether management systems, inspection and robots, factory acceptance, and testing, all of which are important in marine renewable systems. Narec's tidal test facility is based at the River Tees Barrage and is essentially a lock in which the flow of water can be controlled. The site is $6-\mathrm{m}$ wide and has channel depths of between 1 and $7 \mathrm{~m}$. Electrical generator test rigs are available for conventional high-speed machines and also linear direct drive. The Narec Clothier Laboratory provides access to high-voltage test facilities across the transmission and distribution industry. In July 2009, Narec received funding from the UK Department for Energy and Climate Change to develop a full-scale power take-off test rig, which Narec calls Nautilus. In addition to test facilities, Narec provides engineering design consultancy services in all aspects of device development. Narec has gained a broad range of experience as a result of its work with universities and developers, which it is using to contribute to the development of standards and guidelines for the marine industry.

Wave Hub, England Wave Hub (http://www. wavehub.co.uk), a renewable energy project off the north coast of Cornwall in South West England, is being developed by the South West 

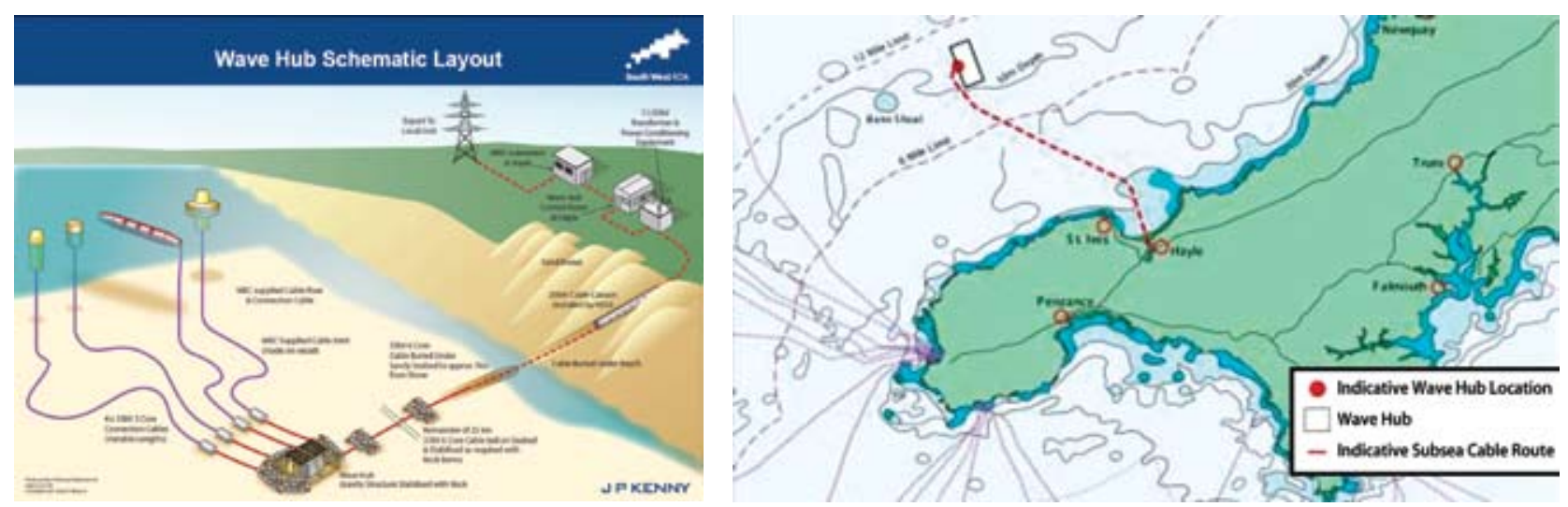

Figure 3. Wave Hub concept (left) and a map of its location (right) off the north coast of Cornwall in South West England.

Regional Development Agency. Wave Hub's main objective is to provide an offshore test facility for arrays of wave energy converters. After single prototype devices have been tested at other facilities such as EMEC or Galway Bay, for example, developers can test arrays at Wave Hub for several years. Essentially, Wave Hub is a subsea connection point for plugging in devices whose power will be transmitted to shore via a single cable to the substation at Hayle. Initially, the system will operate at $11 \mathrm{kV}$, which allows up to $16 \mathrm{MW}$ capacity to be installed. In the long term, Wave Hub will be upgraded to $33 \mathrm{kV}$ so that the capacity can be expanded to $50 \mathrm{MW}$. Figure 3 shows an artist's conception of Wave Hub and a map of its location.

Wave Hub covers an area of $8 \mathrm{~km}^{2}$. It will be possible for more than one developer (up to a maximum of four) to be operational at Wave Hub at any one time. Each developer will be able to lease a $1 \mathrm{~km} \times 2 \mathrm{~km}$ sea area for five years in the first instance, with the potential for extensions. Each developer will be able to generate up to a maximum of 4-5 MW of power. Wave Hub will, on behalf of the developers, enter into a power purchase agreement. Consents for the project were granted in September
2007 , and the funding package was finalized in July 2009. Installation is planned to begin in the summer of 2010 .

\section{Marine Institute}

The Marine Institute (http://www. marine.ie/home/OceanEnergy.htm), based in Galway, Ireland, is working with Sustainable Energy Ireland to implement Ireland's National Ocean Energy Strategy (see http://www. marine.ie/home/services/operational/ oceanenergy/OceanEnergyStrategy.htm), whose objectives are to: (1) support the introduction of ocean energy to the renewables "portfolio" in Ireland, and (2) develop an Irish ocean energy industry sector. The strategy is being implemented in four phases, and is currently in Phase 2:

Phase 1: Development: 2005-2007

Phase 2: Pre-commercial (1): 2007-2010

Phase 3: Pre-commercial (2): 2010-2015

Phase 4: Commercial: 2010-2015

Successful implementation of these phases is expected to lead to the delivery of 75 MW by 2012 and 500 MW by 2020 . Test facilities have been established at HMRC's one-quarter-scale wave site at Galway Bay, and plans are underway for a full-scale, grid-connected wave facility. The Galway Bay site is used by developers as part of Phase 3 in the Development and Evaluation Protocol, and Phase 2 of the National Ocean Energy Strategy. There is no grid connection, and so developers have to provide their own means of processing the power generated. Wave energy data have been measured and are available to developers. The site is 37 hectares $\left(.37 \mathrm{~km}^{2}\right)$ in area and is in $21-24 \mathrm{~m}$ of water. Standards and guidelines have been produced for developers using the site. Currently, two devices have been deployed at the site since 2006: Wavebob and the Ocean Energy Buoy. Although Galway Bay is described as a benign site, 8-m waves were recorded during the storms of January 2007. Plans for a fullscale wave test facility are included in the National Ocean Energy Strategy for Phases 4 and 5 of the Development and Evaluation Protocol. A suitable site has been identified: Belmullet on the northwest coast of Ireland. Preparatory work is ongoing, and it is expected the first devices will be deployed by 2013 .

\section{Nissum Bredning}

Nissum Bredning (http://www.

folkecenter.net/gb/rd/wave-energy) is an offshore test facility in the western Limfjord, Denmark (Figure 4). Opera- 


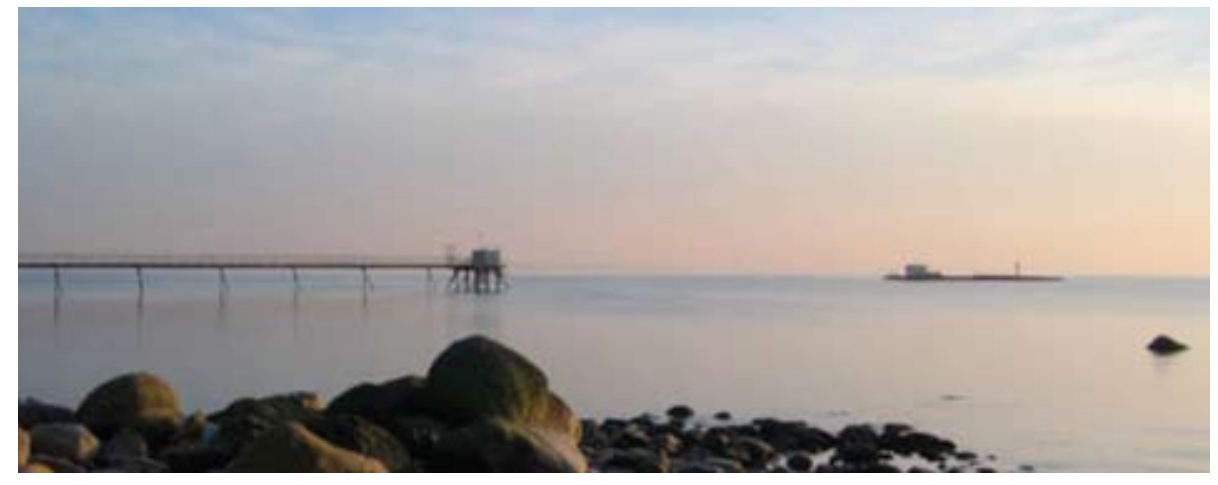

Figure 4. The Nissum Bredning Wave Test Centre in western Limfjord, Denmark, with Wave Dragon on site.

tional since 2000 and funded by the Danish Energy Agency, it is currently operated by the Folkecentre. More than 30 different types of wave power plants have been tested at Nissum Bredning Test Station for periods from a few days up to several years. However, before installing a device at the test center, the developer has to have tested a scale model in a university wave tank. Nissum Bredning is sheltered, allowing the testing of devices at about one-quarter scale. Facilities at the site include craneage, anchorage at 8-m water depth, a dinghy for assisting with device launches, and monitoring equipment for wind speed and wave height.

\section{Wave Power Project}

The Wave Power Project at Lysekil (http://www.el.angstrom.uu.se/ forskningsprojekt/WavePower/ Lysekilsprojektet_E.html) was initiated in early spring 2002 by researchers and $\mathrm{PhD}$ students in the Department for Engineering Science, Division for Electricity, Uppsala University, Sweden. The project has three goals:

1. To verify that the basic technology for a new wave power concept is successful. The concept is based on a linear generator standing on a seabed foundation and tested under realistic, natural conditions.

2. To test an array of buoys varying in material, size, and design. The connected generators will be studied as a unified system for electricity production.

3. To gain knowledge of the effects of this new type of wave power plant on the local environment, for example, commercial and leisure fishing, effects on birds and other marine species, and effects on other marine biological systems.

The project has permission to use a maximum of 10 generators each with an installed capacity of $10 \mathrm{~kW}$, which will be deployed successively from 2005 to 2010 . The complete installation will produce about 300,000 kilowatt-hours per year, equivalent to the yearly consumption of about 20 households. In order to study possible nature conservation and other environmental effects, the project will be expanded to include up to 30 dummy buoys. Consequently, questions about single units and about the area effects of wave power plants can be investigated. Environmental and nature conservation can be taken into account in the design at an early stage without having a negative effect on the technical and economical performance. Finally, the issue of public acceptance will also be monitored.
Florida Atlantic University Center for Ocean Energy Technology

Florida Atlantic University's Center for Ocean Energy Technology (http://coet. fau.edu) is a synergistic partnership among academia, industry, and government laboratories, using the South Florida Testing Facility range in Dania Beach to foster the research, design, development, implementation, testing, and commercialization of cutting-edge ocean energy technologies that are cost-competitive with existing fossilfuel-based power generation. Ocean current, thermal, wave, and tidal-based energy are focus areas for development as renewable power sources. The center's expertise includes ocean engineering, material science, marine biology, physical oceanography, hydrogen engineering, environmental science, ocean operations, and policy. The center will also possess and operate a wide range of assets, including a permanent offshore instrument testing and evaluation range, research vessels, laboratories, and fabrication facilities.

\section{New England Marine Renewable Energy Center}

The New England Marine Renewable Energy Center (MREC; http://www. mrec.umassd.edu) is an organization comprised of academia, government agencies, industry, municipalities, public interest groups, and concerned individuals. MREC's focus is to foster the development of ocean-based renewable energy (wave, tidal current, and ocean wind) through research, development, and demonstration. MREC is assembling a network of technology developers and energy users who will collectively define the needs of this nascent industry and work to bring 
together the required technology, capital, infrastructure, and human resources to implement ocean renewable energy in the most sustainable manner for the region. Inherent in the MREC mission are the following objectives:

1. A world class university research consortium to encourage collaboration, cooperation, and education for marine renewable research

2. Permanent ocean test sites to facilitate research and demonstration of oceanbased renewable technologies

3. An industry user group to elicit research needs, and to assist in advocating for public and private development support

4. Involvement of regulatory and environmental public interest groups to ensure ocean development standards that minimize impact to the ocean ecosystem

5. Education and training to support the marine renewable energy industry.

\section{THE ROLE OF TEST CENTERS AND RESEARCH CLUSTERS IN MEETING KEY CHALLENGES}

Table 3 summarizes the key challenges in wave energy technology development (see Mueller and Wallace, 2008, for details). A technology roadmap to address these challenges published by the UK Energy Research Centre is available at: http://ukerc.rl.ac.uk/ERR0303. $\mathrm{html}$. The predictability of devices is being better understood as a result of a combination of academic and industrial research. Contributing factors to predictability include academic work on numerical and physical convergence; better understanding of resource device interaction in both waves and currents at the same time; design of arrays of wave and tidal energy converters, moorings, and tank testing; and development of combined wave and tank test facilities. The availability of university wave tanks and full-scale test facilities has enabled technology developers to verify the performance of their devices, which allows them to scale up with more confidence.

Advances in manufacturability have been made by those technology developers who have deployed prototypes at sea. In doing so, most developers have

Table 3. Key challenges in wave energy technology development

\begin{tabular}{|c|c|}
\hline Challenge & Priority Advances \\
\hline $\begin{array}{l}\text { Predictability } \\
\text { Understanding the resource and device interaction such } \\
\text { that it delivers predicted design performance }\end{array}$ & $\begin{array}{l}\text { Better resource analysis and weather forecasting; better hydrodynamic } \\
\text { and primary power conversion modeling; better understanding of } \\
\text { floating, founded-wave, and tidal-current device array effects; better } \\
\text { modeling of combined waves and currents }\end{array}$ \\
\hline $\begin{array}{l}\text { Manufacturability } \\
\text { Concepts that can be manufactured within prescribed } \\
\text { costs using existing or new technology }\end{array}$ & $\begin{array}{l}\text { Understand the consequences of increasing scale from } 1 / 100^{\text {th }} \text { to full } \\
\text { size; address turbulence and cavitation effects; develop direct drive and } \\
\text { hydraulic power take-offs, control, and storage }\end{array}$ \\
\hline $\begin{array}{l}\text { Installability } \\
\text { Capability for installation in marine and environmental } \\
\text { conditions using existing or new facilities }\end{array}$ & $\begin{array}{l}\text { Establish fabrication, transport, and installation infrastructure; develop } \\
\text { cost-effective foundations, moorings, and anchorages; develop } \\
\text { electrical connectors and submarine cabling networks; improve } \\
\text { network integration }\end{array}$ \\
\hline $\begin{array}{l}\text { Survivability } \\
\text { Conceived and constructed to survive predicted and } \\
\text { surprise extremes in wind, wave, and tidal current } \\
\text { conditions in any combination }\end{array}$ & $\begin{array}{l}\text { Better statistical analysis and short-term prediction of extremes; design } \\
\text { for cost-effective survival; establish standards, testing, proving, and } \\
\text { certification methods and operate to them }\end{array}$ \\
\hline $\begin{array}{l}\text { Reliability } \\
\text { Capable of reliable operations over predicted lifetime if } \\
\text { maintained as planned }\end{array}$ & $\begin{array}{l}\text { Improve coating, sealing, monitoring, reliability in marine environment; } \\
\text { establish component reliability statistical database }\end{array}$ \\
\hline $\begin{array}{l}\text { Affordability } \\
\text { A lifetime cost that ensures market access and return on } \\
\text { investment in the prevailing economic climate }\end{array}$ & $\begin{array}{l}\text { Develop equitable means of lifetime costing and performance appraisal; } \\
\text { understand cost/survival/performance relationships }\end{array}$ \\
\hline
\end{tabular}


built a number of devices at various scales. Academic work on scaling, turbulence, and power take-off and control have informed the industrial community to enable scale up and the manufacture of prototypes for sea trials. Through deployment at open-sea test sites, developers have learned about actual installation techniques and the impact of the environment on installation and operability. Operators of test sites have gained experience in cabling, electrical infrastructure, and environmental impacts, all of which can be shared with the industry. Research work on environmental monitoring is advancing knowledge of the impact of the operation of devices on the marine environment.

Survivability applies to all components in a device, and knowledge of extreme events is necessary to understand the impact on structure, drive train, and mooring systems. The combination of operational time at sea and engineering design of structures will advance knowledge in this area. Survivability is closely linked to reliability, which also requires operational time to realistically predict component lifetime and time between failures. There have been a limited number of operational hours at sea, making it difficult to estimate reliability with confidence. Current research makes use of existing reliability databases from the offshore oil and gas industry or the defense industry. There is an opportunity to develop test facilities to test components under realistic conditions.

A combination of improved component modeling and physical data obtained from sea trials will assist in the understanding of component survivability and reliability. Collaboration among academics, operators of test facilities, and device developers is important to advance knowledge in both these challenges. Collaboration among academics, developers, and test site operators in programs such as EQUIMAR (Equitable Testing and Evaluation of Marine Energy Extraction Devices; http://www.equimar. org), funded by the EU, is contributing to advances in equitable means of lifetime costing and performance appraisal and will contribute to the challenge of affordability. All groups are working to develop International Electrotechnical Commission (IEC) standards and guidelines to ensure equitable testing of devices, certification of performance, and survivability. Evaluation protocols provide a pre-commercialization development strategy for the industry to follow, and also provide investors with critical information at the various stages of the scaling up of a device. Standards, guidelines, and protocols have a strategic role to play in addressing all the key challenges.

\section{THE FUTURE}

All of the research consortia and test centers described in this paper are assisting the industry to address the key challenges in marine energy technology development. Generic research groupings funded by the EU FP7 program that are investigating the design of components for marine renewable energy systems include EQUIMAR, Wave Energy Planning and Marketing (WAVEPLAM, http://www.waveplam. eu/page, investigating the nontechnical barriers to wave energy), and Components for Ocean Renewable Energy Systems (CORES, http://hmrc. ucc.ie/FP7/cores.html, focusing on new components and concepts for ocean energy converters). Also of note on the US west coast of California is Pacific Gas
\& Electric's Wave Connect, which will serve as a "proving ground" for wave energy devices. In addition, numerous research groups working outside of the activity described in this paper are also making important contributions. Although most of the activity has been in Europe due to favorable government policies toward climate change and the size of the resource in European waters, strong international collaboration stands to benefit all countries with large marine resources, and experience gained within Europe is being shared with other countries, notably the United States, Canada, Taiwan, China, Korea, and Chile. Dialogue between the European marine community and these countries ensures that the establishment of research consortia will complement existing activities. The international outreach activities within Supergen Marine have facilitated the establishment of similar consortia in the United States and Canada. A coherent global R\&D strategy appears to be emerging as a result of such knowledge exchange, which is assisting in the development of a global marine renewable energy industry. 四

\section{REFERENCES}

Bedard, R., P. Mirko, G. Hagerma, B. Polagye, W. Musial, J. Klure, A. von Jouanne, U. Mathur, C. Collar, C. Hopper, and S. Amsden. 2007. North American ocean energy status-March 2007. Paper presented at the $7^{\text {th }}$ European Wave \& Tidal Energy Conference, Porto, Portugal, September 11-14, 2007. Available online at: http://www.oceanenergy.epri.com (accessed March 25, 2010).

Mueller, M.A., and A.R. Wallace. 2008. Enabling science and technology for marine renewable energy. Energy Policy 36(12):4,376-4,382.

Carbon Trust. 2006. Future Marine Energy Results of the Marine Energy Challenge: Cost Competitiveness and Growth of Wave and Tidal Stream Energy. The Carbon Trust, London, UK, 38 pp. 